\title{
Conceptual Entity
}

National Cancer Institute

\section{Source}

National Cancer Institute. Conceptual Entity. NCI Thesaurus. Code C20181.

An organizational header for concepts representing mostly abstract entities. 